\title{
Multi-criteria Approach and Wind Farm Site Selection Analysis for Improving Power Efficiency
}

\author{
Fouad Alhajj Hassan ${ }^{1 *} \bullet$ \\ ${ }^{I}$ Department of Electrical Engineering, Kazan State Power Engineering University, Kazan 420066, Russia
}

Received 26 February 2020; Revised 22 May 2020; Accepted 27 May 2020; Published 01 June 2020

\begin{abstract}
The use of electrical energy is still increasing around the world and is extending to cover more electrical power-based applications. This will lead to more climate change across the globe in the next decades. Thus, renewable energy must be used in an efficient way to reduce the negative effects of these power generators. The location of the wind farm plays a big role in determining the efficiency of the output power. The aim of this research is to study which turbine configuration suits best for a specific location, taking into consideration all the possible constraints. In order to reach our goal, three different turbine configurations are studied with the least possible uncertainties. The optimal configuration is when the wind shear is minimal at the height of the hub, the wake effect is negligible, and the capacity factor is maximal (the economical part is not included). In this study, the Sorochi Gory (located in Tatarstan, Russia) wind farm site will be explained and analysed. The power exponent and capacity factor will be calculated, and the results will be displayed.
\end{abstract}

Keywords: Wind Farm; Wind Shear; Turbines Configuration; Capacity Factor.

\section{Introduction}

Wind farm location is an important factor to be studied before building turbines to get the highest power efficiency. Sorochi Gory is a location where wind turbines will be built; a mast will be placed on the site to measure the wind speed from July 2018 to July 2019 in order to estimate the energy output. In this paper, the power curves are studied, panoramic views in all directions are shown to reflect the shear length, the area will be analysed and information about it will be presented $[1,2]$. Due to confidentiality, some of the values are not shown; however, the calculation procedure and results are presented. The project is intended to produce $150 \mathrm{MW}$ using 60 wind turbines. The three types of turbines are Siemens Gamesa SG 3.4-132 3.465MW, Vestas V126-3.45 MW HTq and Lagerwey L100-2.5 MW.

\subsection{Site Location}

A site is carefully chosen to be suitable to build a wind farm on; primarily, the area should be rural away from any human activity to avoid noise damage and no tall buildings to avoid turbulence. Nearby electric stations are an advantage to connect the wind farm to the grid. The Sorochi Gory project is located approximately $65 \mathrm{~km}$ southeast of the city of Kazan in the republic of Tatarstan. Figure 1 shows the boundary of the wind farm area.

\footnotetext{
* Corresponding author: fouadhajjhassan42@gmail.com

doi) http://dx.doi.org/10. 28991/HEF-2020-01-02-02

> This is an open access article under the CC-BY license (https://creativecommons.org/licenses/by/4.0/).

(C) Authors retain all copyrights.
} 


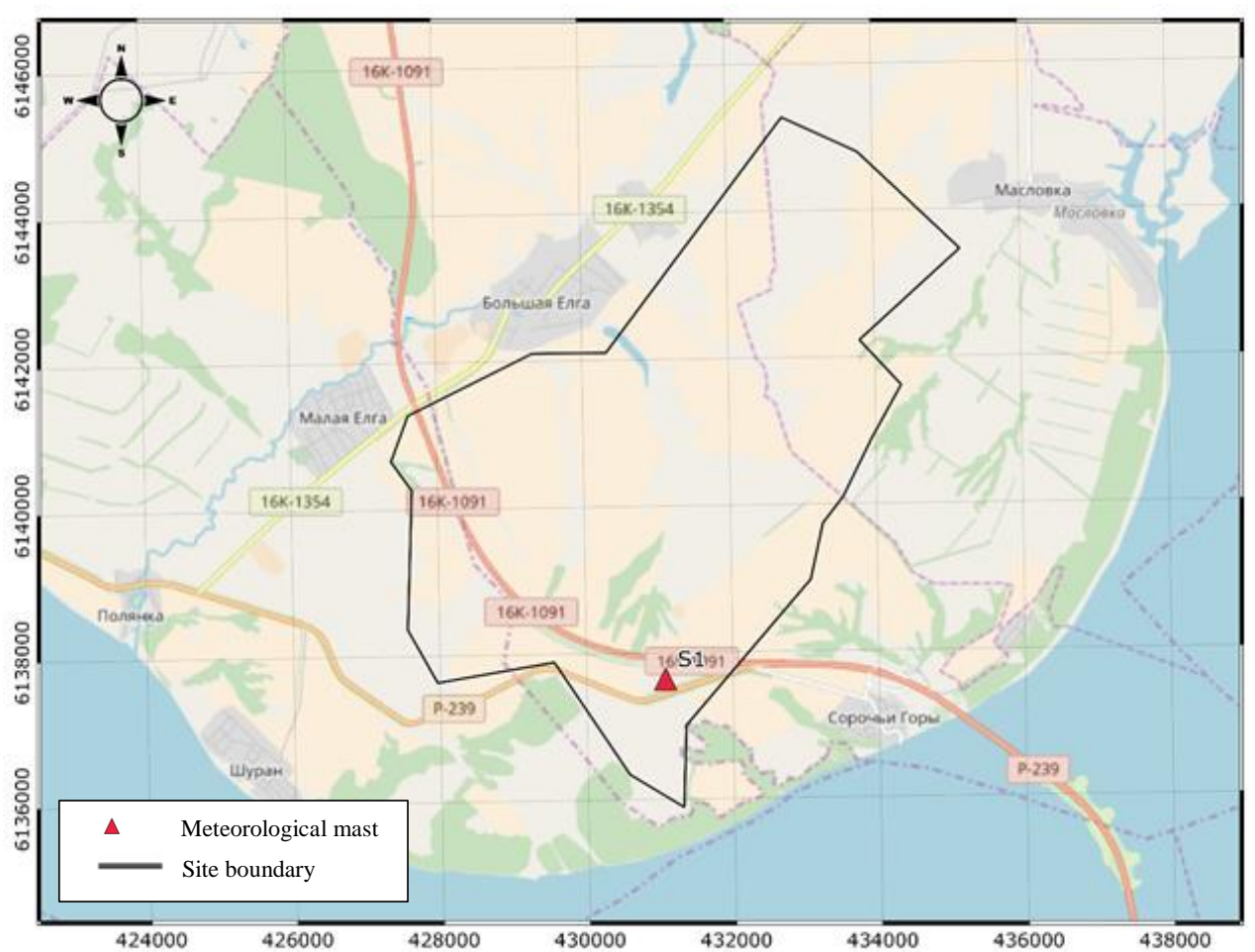

Figure 1. Map of Sorochi Gory wind farm site

It is worth noting that from the south it is bounded by the Kama River. The river delivers low turbulence [3].

\subsection{Wind Speed on the Site}

Figure 2 shows the approximate mean wind speed in Sorochi Gory and the cities around it according to Atlas [4].

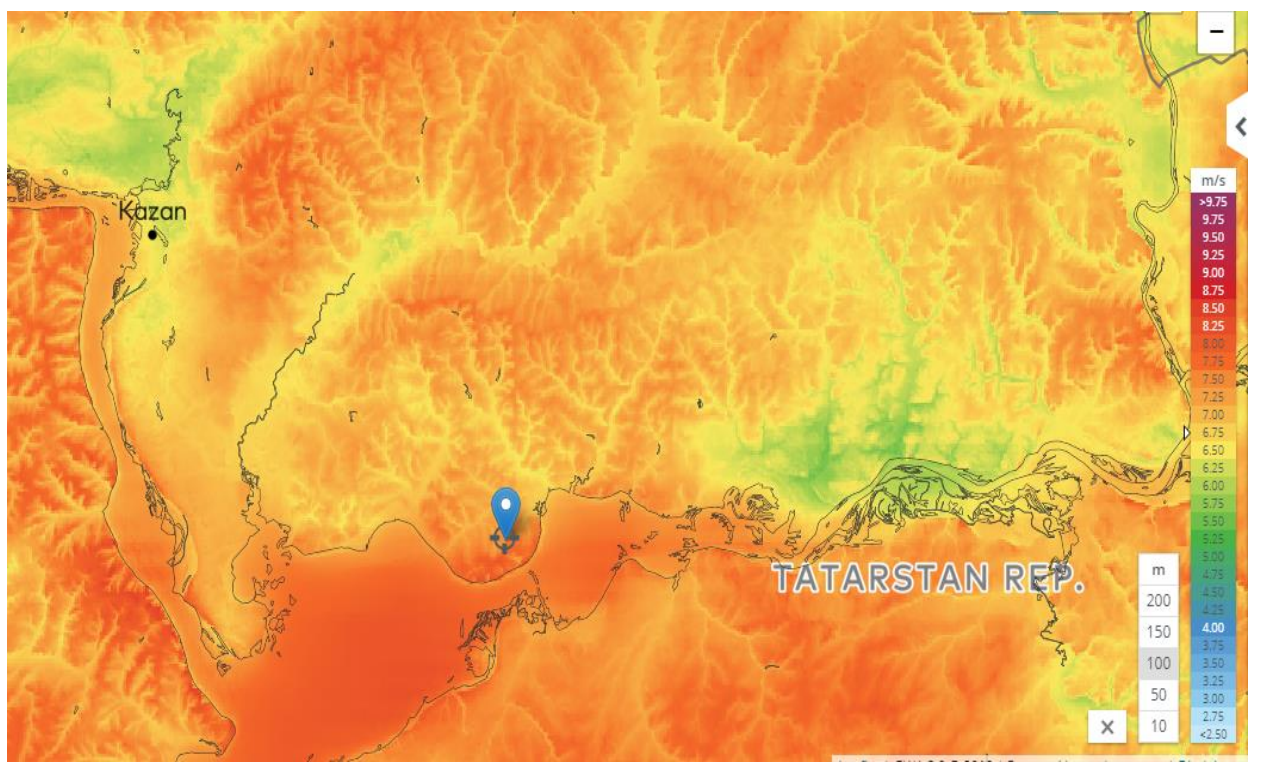

Figure 2. Map presenting the mean wind speed around Tatarstan

As seen in the Figure 2, the wind speed is considerably intense in the referred area with respect to other areas within its boundaries. The area below Sorochi Gory is the Kama River, more studies can be made for an offshore wind farm construction [5]. Figure 3, showing the mean wind speed in Sorochi Gory.

As seen from the Figure 3, the wind speed across the site is between 7.25 and $8 \mathrm{~m} / \mathrm{s}$, which makes it suitable to be categorised in the class 2 according to IEC. 


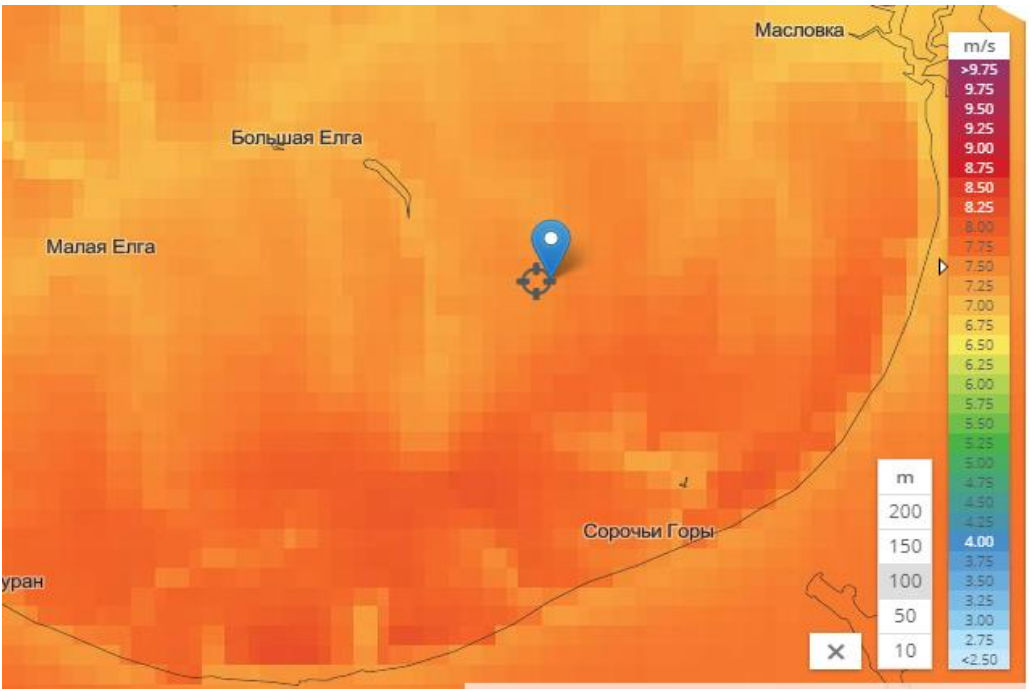

Figure 3. Map presenting the mean wind speed in Sorochi Gory

\subsection{Grid Connection on the Site}

On Sorochi Gory, there is an electrical substation connected to the grid of Tatarstan. Figures 4 and 5 show the grid over Tatarstan, in particular on Sorochi Gory [6].

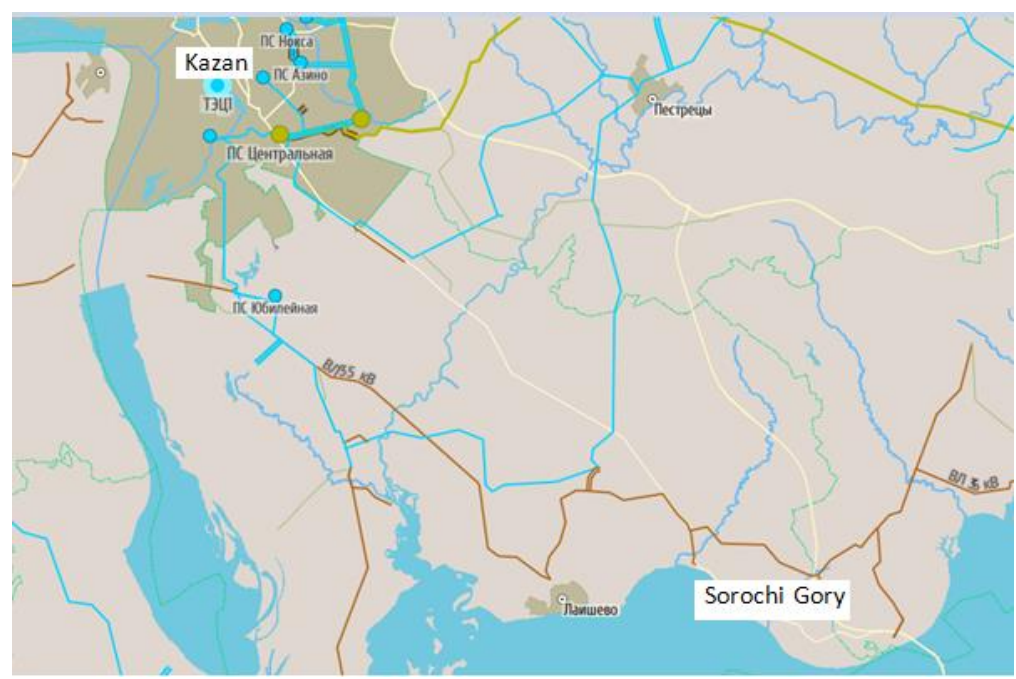

Figure 4. Map presenting the grid over Tatarstan

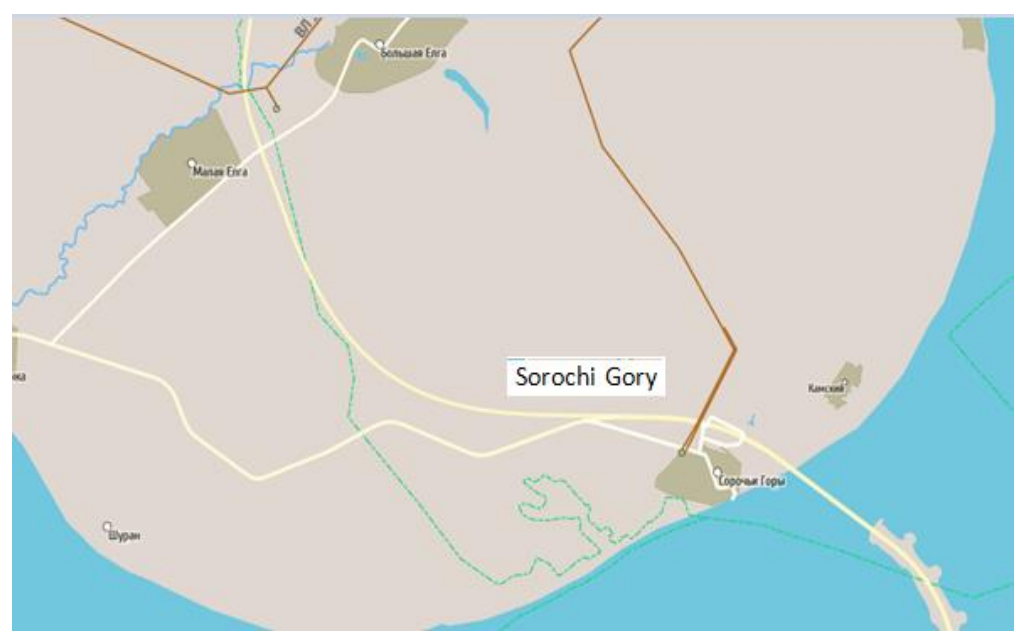

Figure 5. Map presenting the grid over Sorochi Gory

The following figure shows the substation located in Sorochi Gory. 


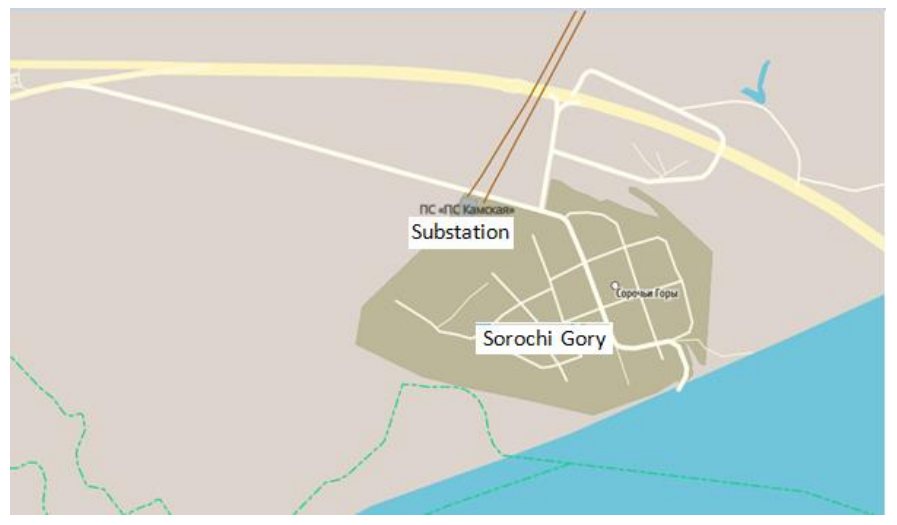

Figure 6. Map showing the substation in Sorochi Gory

A station nearby will reduce the cost of the cables, in addition batteries are not needed.

\section{Panoramic View}

\subsection{Wind Farm Site Information}

The following Figure 7 shows a view of dense forestry immediately northwest of the site.

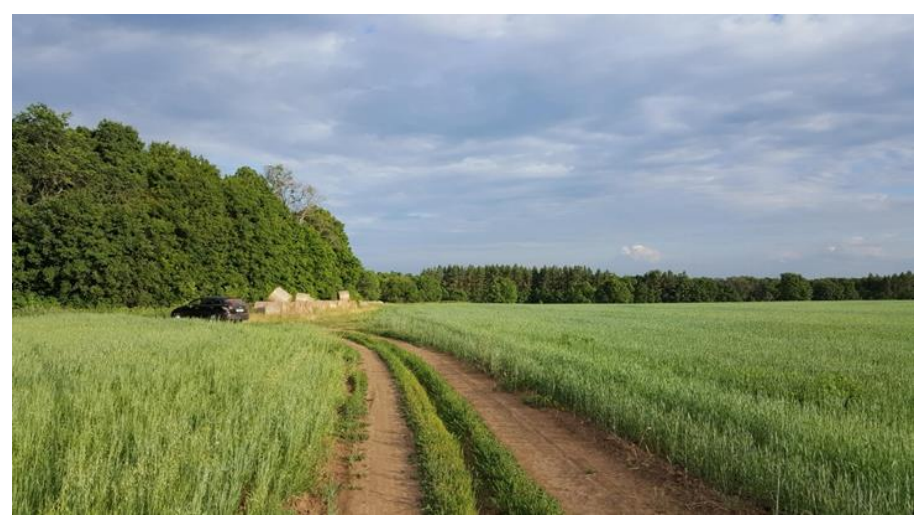

Figure 7. Forestry in the northwest of the site

- Forestry extents have been obtained from aerial photography and site visit observations.

- The trees heights were estimated to be from approximately $9 \mathrm{~m}$ to $12 \mathrm{~m}$.

As concluded the trees height is around $12 \mathrm{~m}$ and no buildings exists, the grace is smoothly spread. To estimate the wind shear shown in the following equation can be used [7]:

$\alpha=\frac{\ln \left(\frac{v_{2}}{v_{1}}\right)}{\ln \left(\frac{h_{2}}{h_{1}}\right)}$

Where $\alpha$ is the wind shear, $h_{2}$ is the height at the top, $h_{1}$ is the height at the bottom, $V_{2}$ is the speed at the top and $V_{1}$ is the speed at the bottom [8]. On the other hand, when an overview of the site is available, the wind shear can be estimated according to the Table 1:

Table 1. The power law exponent $\alpha$ values according to the terrain description [9]

\begin{tabular}{cc}
\hline Terrain description & Power law exponent, $\boldsymbol{\alpha}$ \\
\hline Smooth, hard ground, lake or ocean & 0.1 \\
Short grass on untilled ground & 0.14 \\
Level country with foot-high grass, occasional tree & 0.16 \\
Tall row corps, hedges, a few trees & 0.2 \\
Many trees and occasional buildings & $0.22-0.24$ \\
Wooded country-small towns and suburbs & $0.28-0.3$ \\
Urban areas with tall buildings & 0.4 \\
\hline
\end{tabular}


From the Table 1, according to the description of the site, the wind shear can be estimated to be $\alpha=0.2$. As seen in the pictures of Figure 7, the biome around the mast is relatively smooth, that is why the shear factor $\alpha$ is relatively small which indicates that the wind is not fluctuating heavily [10].

\subsection{Mast Information}

The mast is set at point $(431079,6137641)$ with several sensors at serval heights as seen in the Figure 8 . In the following Figure 8, photographs looking west-southwest and south of the mast are presented.

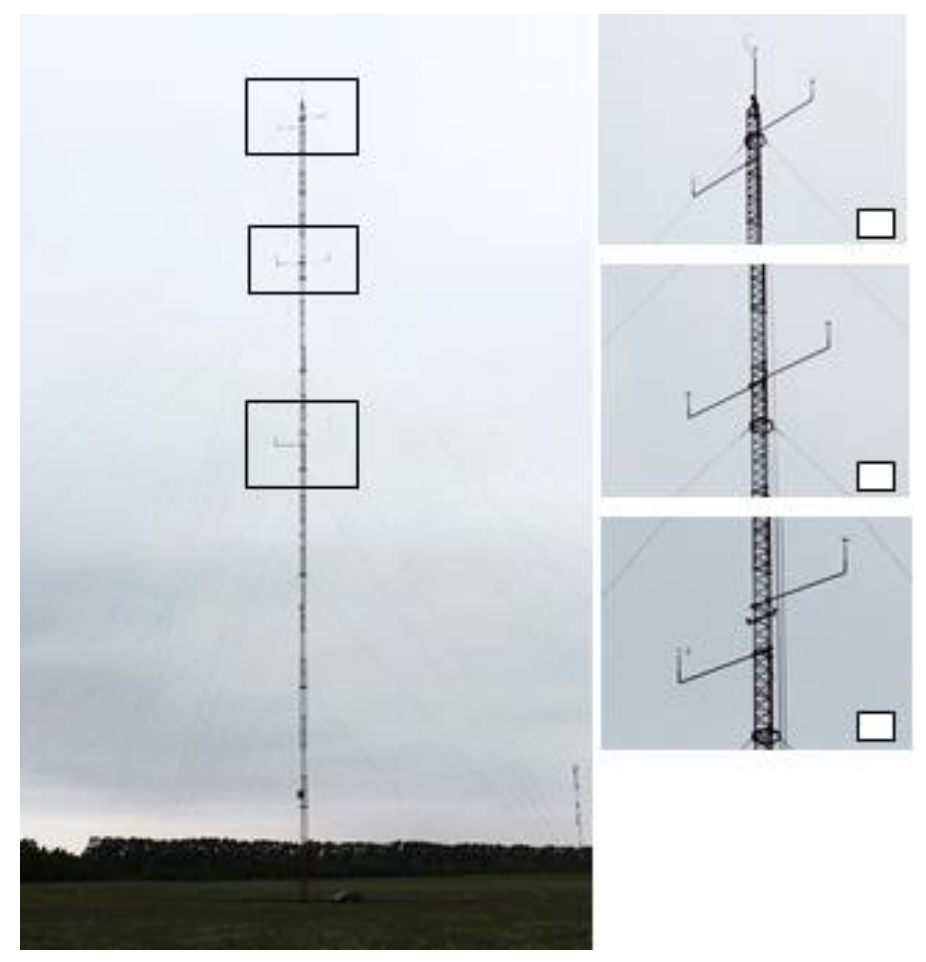

Figure 8. Photographs looking west-southwest and south of the mast

The sensors are set at different heights in order to measure the wind speed and wind direction at several tips. By using, the data of the anemometers in the shear Equation 1, the wind shear $\alpha$ can be precisely calculated. The wind shear Equation 1 should be filled by the proper data, where $h_{2}$ is the height of the higher anemometer $99 \mathrm{~m}, \mathrm{~h}_{1}$ is the height of the lower one $94.3 \mathrm{~m}, \mathrm{~V}_{2}$ is the speed at $h_{2}$ and $\mathrm{V}_{1}$ is the speed at $h_{1}$. Then this repeated for the anemometers at heights $72.6 \mathrm{~m}$ and $94.3 \mathrm{~m} \mathrm{[11].} \mathrm{The} \mathrm{average} \mathrm{wind} \mathrm{shear} \mathrm{is} \mathrm{then} \mathrm{calculated} \mathrm{by} \mathrm{averaging} \mathrm{both} \mathrm{the} \mathrm{shears.}$

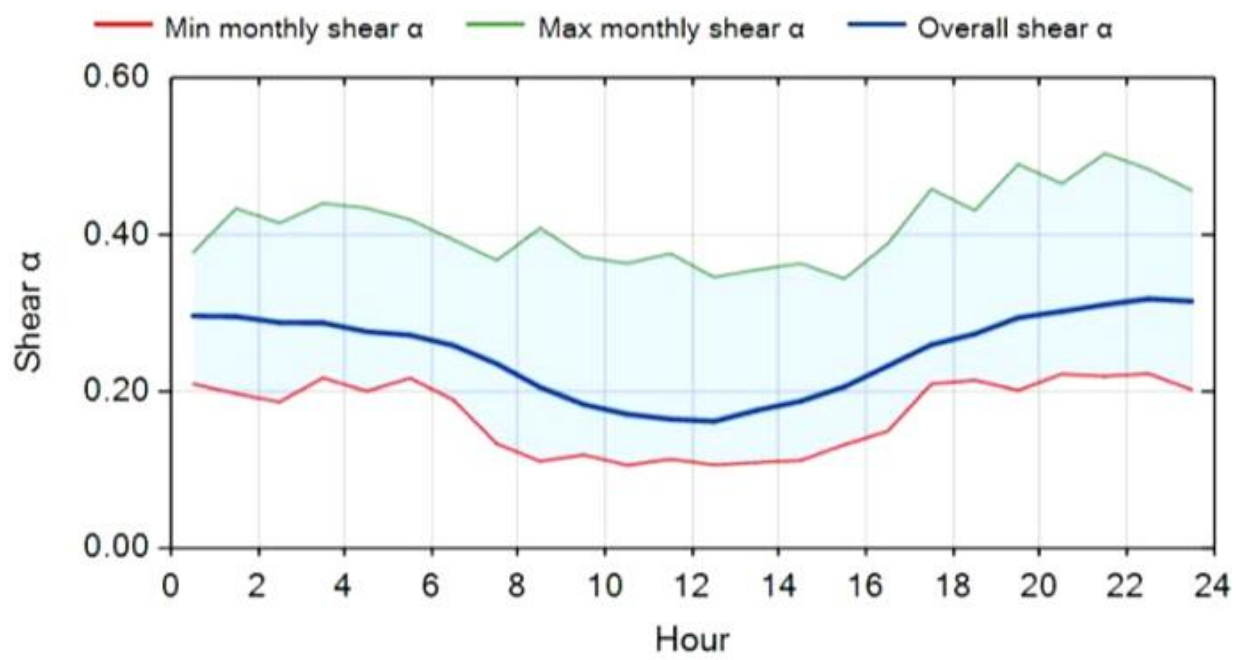

Figure 9. Maximum, minimum and average monthly wind shear

The blue line presents the average wind shear between the maximum $\alpha$ and the minimum $\alpha$. The average is calculated to eliminate the uncertainty as much as possible. 


\section{Factors Affecting the Site}

\subsection{Site Access}

Extreme ecological conditions can affect access to more remote sites, which can affect accessibility. A case of this may be a zone prone to serious snowdrifts during the winter season. The effect on energy will be subjected to the operations and maintenance plans [12].

\subsection{Impact of Trees}

Where obstacles to the flow (for example, trees in closeness to a pole or turbine) are present, it is crucial to consider the impact of these impediments on the wind flow model. The accompanying methodology has, therefore been adopted [13]. Zones of forestry and land cover have been examined, to build up both the area and tallness of trees.

- For every pole and turbine location, a viable decrease in the estimation or hub tallness is assessed, so as to represent the impact of trees as a snag to the wind flow. The determination of these statures depends on the displacement tallness of the trees, the vicinity of the pole or turbine to the trees, and the recurrence of the event of the relevant wind directions.

- Where suitable, a characteristic energy loss factor profile is determined, so as to represent any adjustments in the forestry (because of expected tree expansion or felling) during the initial ten years of the wind farm activity.

- For wind farm locations situated inside or near forestry or zones of trees, the effect of how the trees may change after some time and the impact that this will have on the wind flow over the site, and thus the energy production of the wind farm must be considered. The effect of future felling of trees, whenever known, may likewise need to be surveyed. This loss is normally determined on a site-explicit premise.

\section{Turbines Limitations}

\subsection{Turbine Models}

In the Table 2, the turbine models are present under consideration for the Sorochi Gory project [14].

Table 2. Proposed turbine model parameters

\begin{tabular}{ccccc}
\hline Turbine & $\begin{array}{c}\text { Rated Power } \\
(\mathbf{M W})\end{array}$ & $\begin{array}{c}\text { Hub Height } \\
(\mathbf{m})\end{array}$ & $\begin{array}{c}\mathbf{P C} \text { air density } \\
\left(\mathbf{K g} / \mathbf{m}^{3}\right)\end{array}$ & $\begin{array}{c}\text { Operational } \\
\text { temperature range }\end{array}$ \\
\hline Siemens Gamesa SG 3.4-132 3.465MW & 3.465 & 97 & 1.24 & $-20^{\circ} \mathrm{C}$ to $+40^{\circ} \mathrm{C}$ \\
Vestas V126-3.45 MW HTq & 3.45 & 87 & 1.25 & $-20^{\circ} \mathrm{C}$ to $+45^{\circ} \mathrm{C}$ \\
Lagerwey L100-2.5MW & 2.52 & 99 & 1.225 & $-30^{\circ} \mathrm{C}$ to $+30^{\circ} \mathrm{C}$ \\
\hline
\end{tabular}

\subsection{Turbine Layouts}

The wind farm format was structured with the aim of maximizing the energy output; a single wind farm design was intended for the Siemens Gamesa SG 3.4-132 3.465 MW turbine, as the biggest rotor diameter across the turbine model, the two other turbines models used the same layout for the analysis.

Computational optimization of the wind farm format has in this manner been embraced, utilizing DNV GL's WindFarmer Software. The accompanying limitations have been utilized for this optimization, for the Siemens Gamesa SG 3.4-132 3.465 MW turbine [15]:

- A 6.0 rotor diameter spacing between turbines in the prevailing wind directions;

- A 4.0 rotor diameter spacing between turbines in the non-prevailing wind directions;

- An elliptical constraint is used based on the above criteria;

- Terrain slope lower than $10^{\circ}$;

- A site boundary and presented in Figure 1.2;

- A setback distance of $300 \mathrm{~m}$ from the site boundary; and

- Further setback distances of:

- $50 \mathrm{~m}$ from unpaved internal roads and $200 \mathrm{~m}$ from main roads;

- $100 \mathrm{~m}$ from water areas;

- $200 \mathrm{~m}$ from high voltage lines;

- $300 \mathrm{~m}$ from forestry areas. 
A map of the site showing the excluded zones and the allowed areas for placing wind turbines is presented in Figure 10 .

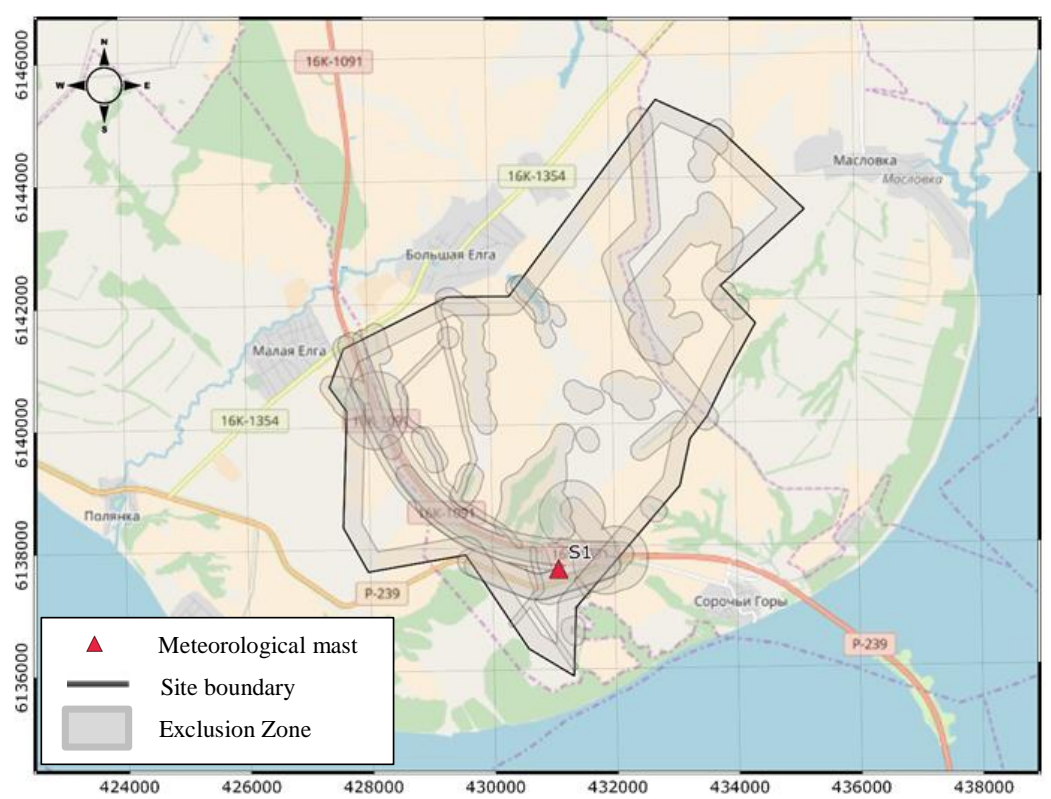

Figure 10. Excluded zones and allowed area for placing wind turbines at the Sorochi Gory Wind Farm site

\section{Turbines Configurations}

The following layout has been designed considering 60 turbine locations, with details given in Table 3 [16, 17].

Table 3. Turbine layout configurations

\begin{tabular}{ccccc}
\hline Configuration Id & Turbine type & Hub height $(\mathbf{m})$ & Number of turbines & Rated power (MW) \\
\hline 1 & Siemens Gamesa SG 3.4-132 3.465 MW & 97 & 60 & 207.9 \\
2 & Vestas V126-3.45 MW HTq & 87 & 60 & 207 \\
3 & Lagerwey L100-2.5 MW & 99 & 60 & 150 \\
\hline
\end{tabular}

The power delivered by a wind turbine is represented through its power curve, where a relation between the wind speed and the power generated is established. Each wind turbine has it is own configuration which presents the power that can be produced at specified wind speeds, the availability of the turbines is assumed at $100 \%$ (no losses due to down time, icing, transformer losses, park effects etc.). The relationship between wind speed and power is defined by a power curve, which is unique to each turbine model.

Figures 11 to 13, illustrate the Siemens Gamesa SG3.4-132, 3.465MW, Vestas V126-3.45 HTq and Vestas V1263.45 HTq wind turbine power curve respectively.

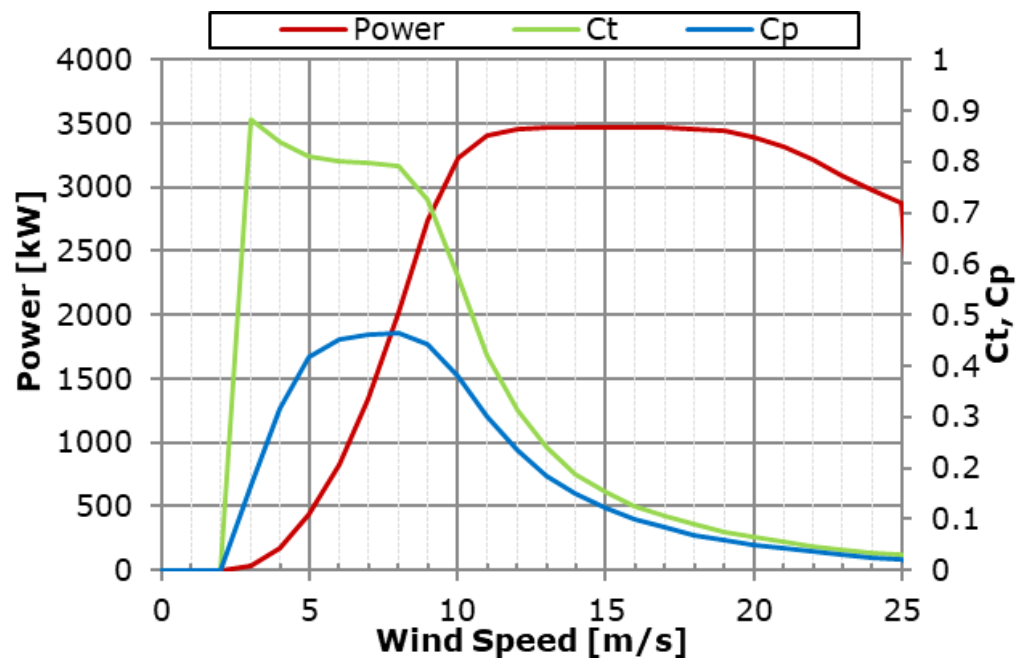

Figure 11. Power curve of the Siemens Gamesa SG3.4-132, 3.465MW turbine 


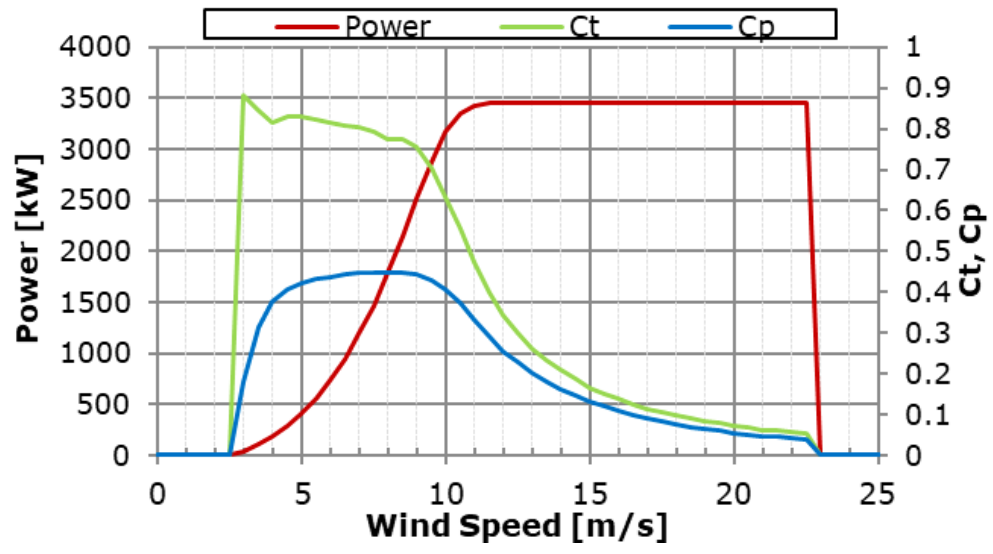

Figure 12. Power curve of the Vestas V126-3.45 HTq, turbine

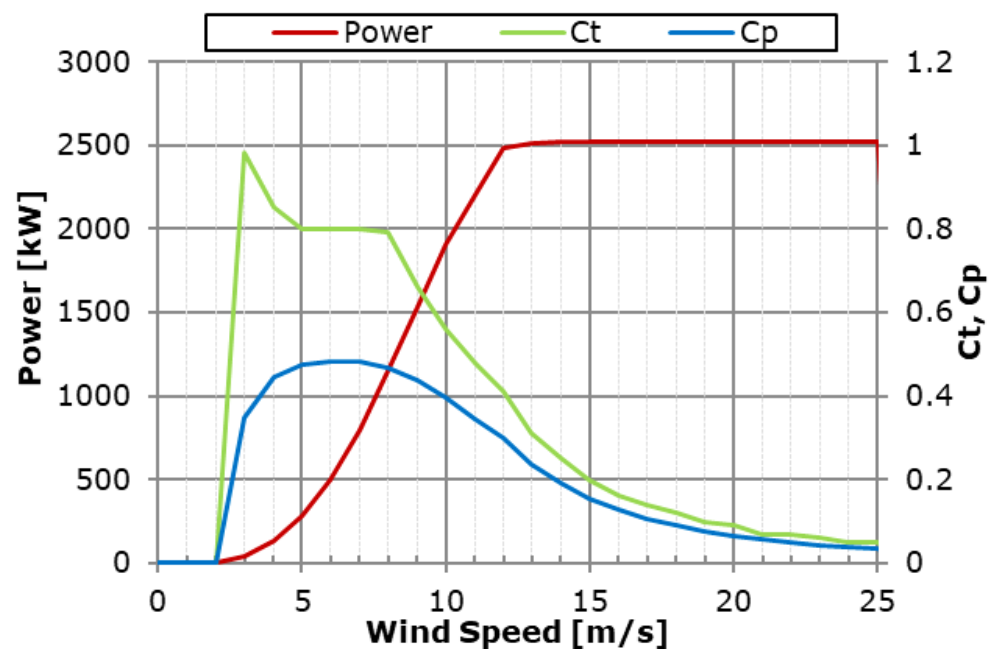

Figure 13. Power curve of the turbine Lagerwey L100-2.5 turbine

A map of the site showing the designed turbine layout and wind measurement location is presented in following Figure 14.

\section{Capacity Factor}

By using the capacity factor Equation (2), the most suitable turbine can be determined.

$C F=\frac{E_{\text {actual }}}{E_{\text {ideal }}}$

where $\mathrm{E}_{\text {actual }}$ is the real power generated by the turbine under specific data and the $\mathrm{E}_{\text {ideal }}$ is the maximum power that can be generated by the turbine.

The actual energy is calculated by multiplying the actual wind speed by the power referred to each speed. This power can be measured by using the power curve of each wind turbine. The ideal energy is calculated by multiplying the maximum wind speed reached by the rated power. The calculation is made for each proposed wind turbine.

Siemens Gamesa SG 3.4-132 3.465 MW

$\mathrm{E}_{\text {actual }}=14,287,966.61$

$\mathrm{E}_{\text {ideal }}=30,353,330.70$

Thus, the capacity factor is $\mathrm{CF}=47 \%$

CF Vestas V126-3.45 HTq

$\mathrm{E}_{\text {actual }}=13,507,385.38$

$\mathrm{E}_{\text {ideal }}=30,221,931.00$

Thus, the capacity factor is $\mathrm{CF}=45 \%$ 


\section{CF Lagerwey L100-2.5 MW}

$\mathrm{E}_{\text {actual }}=8,825,895.03$

$\mathrm{E}_{\text {ideal }}=30,353,330.70$

Thus, the capacity factor is $\mathrm{CF}=29 \%$

The capacity factor for all the proposed turbines is considered really good. The CF of the Lagerwey L100-2.5 MW has the lowest one, and Siemens Gamesa SG 3.4-132 3.465MW is the highest. However, from the economical perspective, a higher $\mathrm{CF}$ will cost much more on the turbine, and a lower one can be the most suitable as a higher capacity factor does not specifically mean that the wind farm investment vs. profit is higher, taking into consideration the price of the turbine.

\section{Map of the Site}

The following observations are made regarding the layout:

- It is noticed that ordinarily higher inter-turbines spacing ought to be applied. It was anyway required to decrease the inter-turbine separating to accomplish the highest wind farm capacity on the site while adjusting the requirement for lower wake losses and therefore lower potential fatigue loads.

- It is noticed that a primer examination of the structure proportionate turbulence intensities was led for the proposed turbines. Hence, it was chosen to receive the consequences of the optimization without any more changes or a decrease in turbine numbers. A portion of the turbine areas in the format is proposed in the prompt region of trees up to roughly $12 \mathrm{~m}$ in height. The height of these trees is significantly less than the proposed hub heights and the potential for elevated turbulence is small.

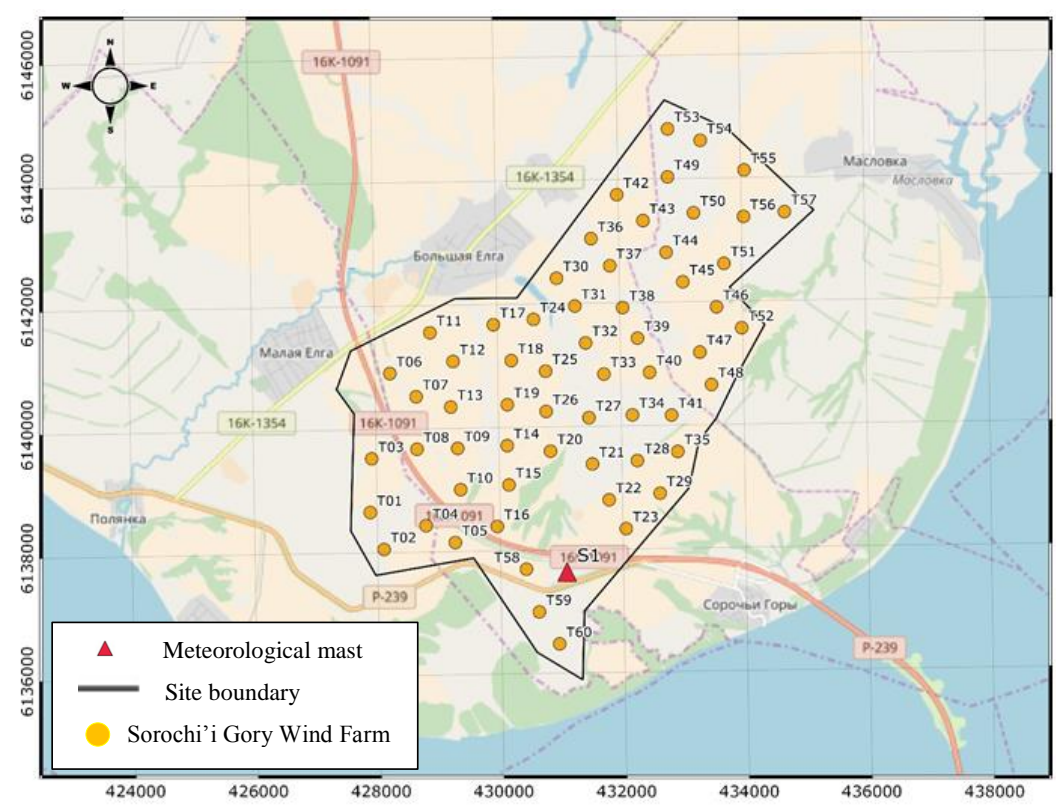

Figure 14. Map of the Sorochi Gory wind farm showing the mast location and the designed turbines layout

Table 4. Shows the terrain contour, roughness and forestry maps for the site

\begin{tabular}{|c|c|c|c|}
\hline Site characteristic & \multicolumn{2}{|c|}{ Resulting input into analysis } & Source \\
\hline \multirow{7}{*}{ Roughness } & \multicolumn{2}{|c|}{ Roughness map with following categories: } & \multirow{7}{*}{$\begin{array}{l}\text { Publicly available satellite imagery } \\
\text { based on Davenport classification. }\end{array}$} \\
\hline & Forested areas & $0.5 \mathrm{~m}$ & \\
\hline & Settlements & $0.3 \mathrm{~m}$ & \\
\hline & Bushes & $0.15 \mathrm{~m}$ & \\
\hline & Marshes & $0.07 \mathrm{~m}$ & \\
\hline & Site and surrounding areas & $0.03 \mathrm{~m}$ & \\
\hline & Water & $0.0002 \mathrm{~m}$ & \\
\hline
\end{tabular}


Table 4, displays the site characteristic.

\section{Future Work}

According to the presented data, the mast lies at a height of around $175 \mathrm{~m}$, while the turbines' elevation shifts from roughly 85 to $175 \mathrm{~m}$. The site pole position is, in this manner, considered not perfectly representative of turbines based at lower elevations, such as a group of turbines situated along the northern edge of the site. It is recommended to do additional measurements at the site, particularly in the northern part, which would serve to reduce these uncertainties. The uncertainty connected with horizontal flow modelling could also be further reduced by employing CFD (Computational Fluid Dynamics) [18].

An economical study should be conducted to estimate the optimal turbine configuration as the capacity factor is shown for each of them. Solar energy can be built around the turbines as the area is not suitable for residential use due to the noise made by the turbines; information about the site is given in Table 5 [19].

Table 5. Information regarding solar energy per year

\begin{tabular}{ccc}
\hline Specific photovoltaic power output & Pvout & $1129 \mathrm{kWh} / \mathrm{kWp}$ \\
Direct normal irradiation & DNI & $1116 \mathrm{kWh} / \mathrm{m}^{2}$ \\
Global horizontal irradiation & GHI & $1118 \mathrm{kWh} / \mathrm{m}^{2}$ \\
Diffuse horizontal irradiation & DIF & $519 \mathrm{kWh} / \mathrm{m}^{2}$ \\
Global titled irradiation at optimum angle & GTI & $1336 \mathrm{kWh} / \mathrm{m}^{2}$ \\
Optimum tilt of PV modules & OPTA & $39 / 180^{\circ}$ \\
Air temperature & TEMP & $4.8^{\circ} \mathrm{C}$ \\
Terrain elevation & ELE & $128 \mathrm{~m}$ \\
\hline
\end{tabular}

\section{Conclusion}

In this paper, the location of the project was presented. The wind speed and the grid's substation were found to be suitable for the project. For precise measures, a mast was built at the point $(431079,6137641)$; a panoramic view of the site including the mast were presented to estimate the wind shear $\alpha$. Some of the factors that affect the site were examined, such as streets, water areas, high voltage lines, and forestry, in order to avoid the turbulence and wake as much as possible. The limitations of wind turbines were discussed and studied to calculate the spacing between them and estimate the locations for each of the wind turbines [20]. The capacity factor shows the different percentages for each of the turbines. Considering it with the price and the length of life of each turbine will lead to the estimation of the optimal wind turbine.

\section{Declarations}

\subsection{Data Availability Statement}

The data presented in this study are available in article.

\subsection{Funding}

The author received no financial support for the research, authorship, and/or publication of this article.

\subsection{Institutional Review Board Statement}

Not applicable.

\subsection{Informed Consent Statement}

Not applicable.

\subsection{Declaration of Competing Interest}

The author declares that there is no conflict of interests regarding the publication of this manuscript. In addition, the ethical issues, including plagiarism, informed consent, misconduct, data fabrication and/or falsification, double publication and/or submission, and redundancies have been completely observed by the author.

\section{References}

[1] Van Haaren, R., \& Fthenakis, V. (2011). GIS-based wind farm site selection using spatial multi-criteria analysis (SMCA): Evaluating the case for New York State. Renewable and Sustainable Energy Reviews, 15(7), 3332-3340. doi:10.1016/j.rser.2011.04.010. 
[2] Blaabjerg, F., Iov, F., Kerekes, T., \& Teodorescu, R. (2010). Trends in power electronics and control of renewable energy systems. Proceedings of 14th International Power Electronics and Motion Control Conference EPE-PEMC 2010. doi:10.1109/epepemc.2010.5606696.

[3] Nasyrov, R. R., Aljendy, R. I., \& Kherbek, T. (2018). Study and analysis of power quality situation in electrical power network. Case study: Lattakia-Syria. 2018 IEEE Conference of Russian Young Researchers in Electrical and Electronic Engineering (EIConRus). doi:10.1109/eiconrus.2018.8317193.

[4] Global Solar Atlas. (2020). Global solar atlas for renewable energy, World Bank Group. Available online: https//www. globalsolaratlas.info (accessed on February 2020).

[5] ENTSO-E. (2020). European Network of Transmission System Operators for Electricity. Available online: https://www. entsoe.eu/data/map (accessed on February 2020).

[6] Almohammed, O. A. M., Timerbaev, N. F., \& Ahmad, B. I. (2019). Heat Pump Application for Water Distillation. 2019 International Multi-Conference on Industrial Engineering and Modern Technologies (FarEastCon). doi:10.1109/fareastcon.2019.8934168.

[7] Firtın, E., Güler, Ö., \& Akdağ, S. A. (2011). Investigation of wind shear coefficients and their effect on electrical energy generation. Applied Energy, 88(11), 4097-4105. doi:10.1016/j.apenergy.2011.05.025.

[8] Hassan, F. A., \& Sidorov, A. (2019). Study of power system stability: Matlab program processing data from Zahrani power plant (Beirut, Lebanon). E3S Web of Conferences, 124, 05011. doi:10.1051/e3sconf/201912405011.

[9] Ray, M. L., Rogers, A. L., \& McGowan, J. G. (2006). Analysis of wind shear models and trends in different terrains. University of Massachusetts, Department of Mechanical and Industrial Engineering, Renewable Energy Research Laboratory.

[10] Wen, B., Wei, S., Wei, K., Yang, W., Peng, Z., \& Chu, F. (2017). Power fluctuation and power loss of wind turbines due to wind shear and tower shadow. Frontiers of Mechanical Engineering, 12(3), 321-332. doi:10.1007/s11465-017-0434-1.

[11] Alzakkar, A. M.-N., Valeev, I. M., Mestnikov, N. P., \& Nurullin, E. G. (2019). The Artificial Power System Networks Stability Control Using the Technology of Neural Network. E3S Web of Conferences, 124, 05002. doi:10.1051/e3sconf/201912405002.

[12] Jeekel, H. (2012). Adaptation to climate change. Conference of European directors of roads. Project Group on Climate Change. Available online: https://climate-adapt.eea.europa.eu/metadata/organisations/conference-of-european-directors-ofroads/11270918 (accessed on February 2020).

[13] Heisler, G. M. (1990). Mean wind speed below building height in residential neighborhoods with different tree densities. ASHRAE Transactions, 96(1), 1389-1396.

[14] Alibeiki, E., \& Khosravi, A. (2019). Modelling and Control of 6MG Siemens Wind Turbine Blades Angle and Rotor Speed. International Journal on Electrical Engineering \& Informatics, 11(1), 80-100.

[15] Ali, N., Hamilton, N., DeLucia, D., \& Bayoán Cal, R. (2018). Assessing spacing impact on coherent features in a wind turbine array boundary layer. Wind Energy Science, 3(1), 43-56. doi:10.5194/wes-3-43-2018.

[16] Arias-Rosales, A., \& Osorio-Gómez, G. (2018). Wind turbine selection method based on the statistical analysis of nominal specifications for estimating the cost of energy. Applied Energy, 228, 980-998. doi:10.1016/j.apenergy.2018.06.103.

[17] Allhibi, H., Chowdhury, H., Zaid, M., Loganathan, B., \& Alam, F. (2019). Prospect of wind energy utilization in Saudi Arabia: A review. Energy Procedia, 160, 746-751. doi:10.1016/j.egypro.2019.02.184.

[18] Sanderse, B., Pijl, S. P., \& Koren, B. (2011). Review of computational fluid dynamics for wind turbine wake aerodynamics. Wind Energy, 14(7), 799-819. doi:10.1002/we.458.

[19] Global Solar Atlas. (2020). Location of the Soroch'i Gory, Russia. Available online: https://globalsolaratlas.info/map? $c=55.416738,49.792099,11 \& s=55.37911,49.952774 \& m=$ site (accessed on January 2020).

[20] Alzakkar, A., Hassan, F. A., \& Mestnikov, N. (2020). Support of Frequency Stability in Electrical Power System at Voltage 400 kV in Syria. Advances in Automation II, 891-902. doi:10.1007/978-3-030-71119-1_86. 